\title{
Dietary Blueberry and Soluble Fiber Improve Serum Antioxidant and Adipokine Biomarkers and Lipid Peroxidation in Pregnant Women with Obesity and at Risk for Gestational Diabetes
}

\author{
Arpita Basu ${ }^{1, *}$, Jeannette Crew ${ }^{1}$, Jeffrey L. Ebersole ${ }^{2}{ }^{\mathbb{D}}$, Jefferson W. Kinney ${ }^{3}$, Arnold M. Salazar ${ }^{3}$, \\ Petar Planinic ${ }^{4,5}$ and James M. Alexander 4
}

Citation: Basu, A.; Crew, J.; Ebersole, J.L.; Kinney, J.W.; Salazar, A.M.; Planinic, P.; Alexander, J.M. Dietary Blueberry and Soluble Fiber Improve Serum Antioxidant and Adipokine Biomarkers and Lipid Peroxidation in Pregnant Women with Obesity and at Risk for Gestational Diabetes. Antioxidants 2021, 10, 1318. https:// doi.org/10.3390/antiox10081318

Academic Editors: Marco G. Alves, Pedro F. Oliveira and Luis Crisostomo

Received: 4 August 2021

Accepted: 20 August 2021

Published: 22 August 2021

Publisher's Note: MDPI stays neutral with regard to jurisdictional claims in published maps and institutional affiliations.

Copyright: (c) 2021 by the authors. Licensee MDPI, Basel, Switzerland. This article is an open access article distributed under the terms and conditions of the Creative Commons Attribution (CC BY) license (https:// creativecommons.org/licenses/by/ $4.0 /)$.
1 Department of Kinesiology and Nutrition Sciences, University of Nevada at Las Vegas, Las Vegas, NV 89154, USA; crewj1@unlv.nevada.edu

2 School of Dental Medicine, University of Nevada at Las Vegas, Las Vegas, NV 89106, USA; jeffrey.ebersole@unlv.edu

3 Department of Brain Health, University of Nevada at Las Vegas, Las Vegas, NV 89154, USA; Jefferson.Kinney@unlv.edu (J.W.K.); arnold.salazar@unlv.edu (A.M.S.)

4 Department of Obstetrics \& Gynecology, Kirk Kerkorian School of Medicine, University of Nevada at Las Vegas, Las Vegas, NV 89102, USA; pplaninic@gmail.com (P.P.); james.alexander@unlv.edu (J.M.A.)

5 Valley Health System, Las Vegas, NV 89119, USA

* Correspondence: arpita.basu@unlv.edu; Tel.: +1-702-895-4576; Fax: +1-702-895-1500

\begin{abstract}
Pregnancies affected by obesity are at high risk for developing metabolic complications with oxidative stress and adipocyte dysfunction contributing to the underlying pathologies. Few studies have examined the role of dietary interventions, especially those involving antioxidants including polyphenolic flavonoids found in fruits and vegetables on these pathologies in high-risk pregnant women. We conducted an 18 gestation-week randomized controlled trial to examine the effects of a dietary intervention comprising of whole blueberries and soluble fiber vs. control (standard prenatal care) on biomarkers of oxidative stress/antioxidant status and adipocyte and hormonal functions in pregnant women with obesity $(n=34)$. Serum samples were collected at baseline $(<20$ gestation weeks) and at the end of the study period (32-26 gestation weeks). Study findings showed maternal serum glutathione and antioxidant capacity to be significantly increased, and malondialdehyde to be decreased in the dietary intervention vs. control group (all $p<0.05)$. Among the adipokine biomarkers, serum plasminogen activator inhibitor- 1 and visfatin, as biomarkers of adipocyte dysfunction and insulin resistance, were also decreased following dietary intervention (all $p<0.05$ ). These findings support the need for supplementing maternal diets with berries and fiber to improve oxidative stress and risks of metabolic complications during pregnancy.
\end{abstract}

Keywords: pregnancy; obesity; glutathione; blueberries; adipokines; malondialdehyde

\section{Introduction}

Maternal obesity has been shown to increase pregnancy complications and increase the risk of gestational diabetes mellitus (GDM) with its well-studied complications including increased risk of fetal macrosomia, shoulder dystocia with injury to the delivering fetus, and neonatal hypoglycemia [1,2]. Diet and lifestyle factors are the cornerstone of weight management in pregnancy and a decrease in excess gestational weight gain has been demonstrated to reduce pregnancy complications and lowers the risk of GDM [3]. Our previous study has focused on clinical endpoints including overall weight gain during pregnancy and clinical outcomes as well as impact on maternal glucose and lipid values $[4,5]$. However, little attention has been given to the impact of dietary interventions on biomarkers of antioxidant and endocrine status in pregnancy. 
Oxidative stress and antioxidant status play an important role in normal pregnancy, as well as in complications, such as GDM and abortions [6]. Normal pregnancy is associated with an increase in oxidative stress as well as an increased synthesis and activities of antioxidant enzymes to facilitate the placental and fetal development and related metabolic functions [7,8]. An imbalance in antioxidant status and lipid peroxidation has been reported in pregnancies complicated by GDM vs. healthy pregnant women $[9,10]$. In these studies, lipid peroxidation measured as malondialdehyde (MDA) was elevated, and antioxidant cofactors, such as glutathione or selenium was reduced, while antioxidant enzymes were mostly non-different or increased to counteract elevated oxidative stress. Again, most of these studies were conducted in women with pregnancy complications, and thus, little is known about how maternal obesity, and dietary antioxidants affect oxidative stress and antioxidant biomarkers in early vs. late pregnancies. In a case-control study of obese and lean pregnant women ( $n=15$ /group), a high ratio of oxidized and reduced glutathione was reported in obese mothers vs. lean controls at mid-gestation [11]. In another cross-sectional study of women with pre-gestational normal weight or obesity, placental expression of the glutathione peroxidase activity was lower in obese vs. normal weight women [12]. In addition, increasing adiposity can also lead to perturbations in metabolism via secretion of adipokines and hormones, such as leptin, plasminogen activator inhibitor-1 (PAI-1), resistin, and visfatin, which have been associated with increased risks of GDM and related pregnancy complications [13-15]. These biomarkers, reflecting maternal oxidative stress/antioxidant status and adiposity and metabolic functions must be evaluated during high-risk pregnancies. However, there is a scarcity of data on the role of diet and lifestyle interventions on these biomarkers during pregnancy, and this leads to the scope of the current study. We selected a panel of antioxidant enzymes/oxidative stress markers, cofactors and adipokines based on their observed responses to dietary interventions involving polyphenols in clinical studies reported by our group, [16-18] as well as by others [19,20] in adults with obesity or the metabolic syndrome.

Among the dietary bioactive compounds that have been shown to exert antioxidant effects and reduce cardiometabolic risks, dietary berries have shown some promising effects in clinical and observational studies [21-23]. Our group conducted several trials and reported improved cardiometabolic risks in non-pregnant adults following dietary berry intervention, primarily as blueberries, strawberries, or cranberry juice [24-26]. In addition, soluble fiber which is an essential component of berries and shown to be beneficial in diabetes [27,28] is not consumed at adequate levels by pregnant women [29]. Keeping in view the lack of such studies in pregnant women with obesity and cardiometabolic risks, we performed a clinical trial to examine effects following dietary blueberry and soluble fiber supplementation vs. standard prenatal care as control. Results showed improvements in excess gestational weight gain (GWG), blood glucose, and C-reactive protein as previously reported [4]. We aimed to examine the effects of this dietary intervention on antioxidant/oxidative stress, hormonal, and adipokine biomarkers in serum samples from the same group of women.

\section{Methods}

\subsection{Study Design and Participants}

The study design has been described in detail previously [4]. Briefly, this RCT was conducted at the Department of Obstetrics and Gynecology at the UNLV School of Medicine. This was a randomized parallel arm study in which participants were randomized to one of two groups: intervention (blueberry + soluble fiber) or control (standard prenatal care) group. The study was approved by the Human Ethics Committee at UNLV (IRB\#1155039). All participants provided informed consent for the study. The inclusion and exclusion criteria have been previously described [4]. Briefly, eligibility criteria involved maternal obesity (BMI $\geq 30)$ and gestational age $<20$ weeks with high risk for GDM, singleton pregnancy, and no pre-gestational chronic conditions. Samples for this study were collected at baseline (<20 weeks gestation) and at end of the 18-week intervention (32-36 weeks 
gestation). Participants in the intervention group were supplemented with 2 cups of whole blueberries and $12 \mathrm{~g}$ of soluble fiber (partially hydrolyzed guar gum; Nutrisource ${ }^{\circledR}$ Nestle Health Science) daily for 18 weeks. This dose of fiber was selected to supplement the habitual low fiber intake of our participants and meet the dietary fiber requirements of approximately 30-35 g/day [30]. The nutritional value has been previously reported with the blueberries adding approximately $160 \mathrm{kcal}, 1600 \mathrm{mg}$ of total polyphenols, and $700 \mathrm{mg}$ of anthocyanins to the maternal diet [4]. Dietary intakes were recorded based on 24-h food recalls throughout the study.

\subsection{Antioxidant Biomarkers}

Antioxidant biomarkers were measured in maternal stored serum samples using procedures as follows: serum catalase was measured using Catalase-520 (Oxis Research, Portland, Oregon) spectrophotometric assay based on the manufacturer's protocol. The average inter-assay CV was $5.6 \%$. Glutathione peroxidase (GPX) was measured by using GPx-340 (Oxis Research) based on the manufacturer's protocol. The average inter-assay CV was $6.3 \%$. Glutathione reductase (GR) and superoxide dismutase (SOD) activity were measured using commercially available kits (Cayman Chemical, Ann Arbor, Michigan) in accordance with the manufacturer's protocol. The average inter-assay CV was 4.5 and $5.3 \%$, respectively. Reduced glutathione was measured as previously described by Beutler et al. [31] based on the absorbance of the yellow thiolate anion at $412 \mathrm{~nm}$. The average interassay CV was $4.3 \%$. Serum antioxidant capacity was measured using the metmyoglobin assay developed by Miller et al. [32]. The average inter-assay CV was 6.8\%. Serum nitrite was measured using the Griess Reagent System (Promega Corporation, Madison, WI) with a mean inter-assay CV of $4.6 \%$. Serum malondialdehyde (MDA) levels were measured by the method of Jain et al. [33] based on the reaction of MDA with thiobarbituric acid to produce a complex that can be determined spectrophotometrically at $532 \mathrm{~nm}$.

\subsection{Adipokine and Hormonal Biomarkers}

Adipokine and hormonal biomarkers were measured in maternal serum samples using Bio-Plex Pro ${ }^{\mathrm{TM}}$ Human Diabetes Panel magnetic bead assays (Bio-Rad Laboratories, Hercules, CA, USA), in accordance with the manufacturer's instructions with modifications as previously described [17]. The variables measured and their corresponding intra-assay CVs were C-peptide $\sim 3 \%$, ghrelin $\sim 4 \%$, gastric inhibitory polypeptide (GIP) $\sim 6 \%$, glucagonlike peptide-1 (GLP-1) $\sim 4.5 \%$, glucagon $\sim 5 \%$, leptin $\sim 4 \%$, plasminogen activator inhibitor-1 (PAI-1) $\sim 3 \%$, resistin $\sim 4 \%$, and visfatin $\sim 5 \%$.

\subsection{Dietary Intake of Antioxidants}

Maternal dietary intakes of micronutrient trace elements with a role in antioxidant/oxidative stress pathways and enzyme activities (iron, copper, zinc, selenium, manganese) were determined using ESHA's Food Processor ${ }^{\circledR}$ Nutrition Analysis software. Participants were asked to maintain their 24-h food recalls for three days per week at baseline and at the end of study. The antioxidant vitamins, macronutrients, and caloric intake have been previously described [4].

\subsection{Statistical Analysis}

Descriptive statistics were calculated data that have been presented as means \pm standard deviations for the continuous variables. Our primary objective for the current analysis was to determine if the antioxidant and adipokine biomarkers were significantly different between the dietary intervention and control groups over the period of the 18 gestation weeks of the study. To address this primary question, we employed a mixed model ANOVA to determine the effects of time, treatment (group), and interaction. Outcomes were modeled as repeated measures, with the subject as a random effect and with unstructured variance for treatment/time. We also conducted a secondary analysis to examine if there were any significant correlations among selected antioxidant and adipokine biomarkers in 
a model adjusted for maternal age, BMI and prenatal vitamin use in pooled analysis of all participants. To address this secondary question, we used a Pearson correlation coefficients analysis. As previously reported, we had $80 \%$ power to detect differences with at least 12 participants per group in this trial [4]. All $p$-values were two-tailed, and main effects and interaction effects were considered if $<0.05$. Analyses were performed using SAS (version 9.4; SAS Institute Inc., Cary, NC, USA).

\section{Results}

The baseline characteristics of the study participants have been previously described and a total of 34 women completed the trial [4]. Briefly, women in both groups had a baseline BMI > 30, were primarily of Hispanic origin and the prevalence of prenatal vitamin use was $35 \%$ at baseline. As previously reported, we observed a significant decrease in GWG, CRP and postprandial blood glucose in the intervention vs. control group [4].

Table 1 presents the maternal serum antioxidant biomarkers at baseline and end of the study. Among the antioxidant biomarkers, maternal serum glutathione and antioxidant capacity were significantly increased at the end of dietary intervention vs. control group. In addition, MDA significantly decreased following the dietary intervention vs. control $(p<0.05)$. No statistical differences were noted in case of maternal antioxidant enzyme activities (catalase, GR, GPX, and SOD) between the two groups.

Table 1. Serum antioxidants and oxidative stress biomarkers in women with obesity and at risk for gestational diabetes in dietary intervention vs. control group for a period of 18 gestation weeks.

\begin{tabular}{|c|c|c|c|}
\hline Variable by Time & Intervention ${ }^{1}$ & Control $^{2}$ & $\begin{array}{l}p \text {-Value }{ }^{3} \\
\text { (Group) }\end{array}$ \\
\hline \multicolumn{4}{|l|}{ Serum catalase, $\mathrm{U} / \mathrm{mL}$} \\
\hline Baseline & $48 \pm 13$ & $56 \pm 15$ & 0.27 \\
\hline End & $62 \pm 14$ & $47 \pm 10$ & \\
\hline \multicolumn{4}{|c|}{ Serum glutathione, $\mu \mathrm{M}^{*}$} \\
\hline Baseline & $880 \pm 320$ & $914 \pm 370$ & 0.03 \\
\hline End & $1236 \pm 612$ & $1107 \pm 532$ & \\
\hline \multicolumn{4}{|c|}{ Serum GR, $\mathrm{nmol} / \mathrm{min} / \mathrm{mL}$} \\
\hline Baseline & $65 \pm 21$ & $72 \pm 21$ & 0.44 \\
\hline End & $54 \pm 18$ & $68 \pm 19$ & \\
\hline \multicolumn{4}{|l|}{ Serum GPX, mU/mL } \\
\hline Baseline & $18 \pm 8$ & $22 \pm 10$ & 0.34 \\
\hline End & $24 \pm 11$ & $31 \pm 15$ & \\
\hline \multicolumn{4}{|l|}{ Serum SOD, U/mL } \\
\hline Baseline & $0.04 \pm 0.03$ & $0.05 \pm 0.03$ & 0.39 \\
\hline End & $0.03 \pm 0.02$ & $0.04 \pm 0.02$ & \\
\hline \multicolumn{4}{|l|}{ Serum nitrite, $\mu \mathrm{M}$} \\
\hline Baseline & $21 \pm 12$ & $31 \pm 11$ & 0.31 \\
\hline End & $28 \pm 15$ & $25 \pm 9$ & \\
\hline \multicolumn{4}{|c|}{$\begin{array}{l}\text { Serum antioxidant capacity, } \\
\mu \mathrm{mol} / \mathrm{L}\end{array}$} \\
\hline Baseline & $3.6 \pm 2.2$ & $4.8 \pm 3.2$ & 0.01 \\
\hline End & $6.2 \pm 4.5$ & $5.5 \pm 3.5$ & \\
\hline \multicolumn{4}{|c|}{ Serum MDA, $\mathrm{nmol} / \mathrm{mL}^{*}$} \\
\hline Baseline & $4.23 \pm 2.31$ & $5.13 \pm 3.21$ & 0.02 \\
\hline End & $2.45 \pm 1.18$ & $4.65 \pm 2.18$ & \\
\hline
\end{tabular}

Data presented as means \pm SD. $\mathrm{N}=17$ /group. Abbreviations: $\mathrm{GR}=$ glutathione reductase; GPX = glutathione peroxidase;

$\mathrm{MDA}=$ malondialdehyde; PAI-1 = plasminogen activator inhibitor-1; SOD = superoxide dismutase. ${ }^{1}$ Blueberry + soluble fiber. ${ }^{2}$ Standard prenatal care. ${ }^{3}$ P from mixed model ANOVA. $p<0.05$ in bold font. ${ }^{*}$ Significant time effect; different from baseline $(p<0.05)$. 
As shown in Table 2, among the maternal adipokines and hormonal biomarkers, maternal serum PAI-1 and visfatin were significantly decreased at the end of dietary intervention vs. control group $(p<0.05)$.

Table 2. Serum adipokines and hormonal markers in women with obesity and at risk for gestational diabetes in dietary intervention vs. control group for a period of 18 gestation weeks.

\begin{tabular}{|c|c|c|c|}
\hline Variable by Time & Intervention ${ }^{1}$ & Control $^{2}$ & $\begin{array}{c}p \text {-Value }{ }^{3} \\
\text { (Group) }\end{array}$ \\
\hline \multicolumn{4}{|l|}{ Serum C-peptide, $\mathrm{pg} / \mathrm{mL}$} \\
\hline Baseline & $2801 \pm 1159$ & $3081 \pm 1660$ & 0.56 \\
\hline End & $2422 \pm 1227$ & $2517 \pm 1289$ & \\
\hline \multicolumn{4}{|l|}{ Serum ghrelin, $\mathrm{pg} / \mathrm{mL}$} \\
\hline Baseline & $242 \pm 187$ & $178 \pm 159$ & 0.37 \\
\hline End & $197 \pm 206$ & $199 \pm 189$ & \\
\hline \multicolumn{4}{|l|}{ Serum GIP, pg/mL } \\
\hline Baseline & $1027 \pm 432$ & $1103 \pm 705$ & 0.42 \\
\hline End & $927 \pm 469$ & $1080 \pm 632$ & \\
\hline \multicolumn{4}{|l|}{ Serum GLP-1, pg/mL * } \\
\hline Baseline & $664 \pm 95$ & $558 \pm 152$ & 0.37 \\
\hline End & $417 \pm 99$ & $448 \pm 112$ & \\
\hline \multicolumn{4}{|c|}{ Serum glucagon, $\mathrm{pg} / \mathrm{mL}^{*}$} \\
\hline Baseline & $1090 \pm 171$ & $1091 \pm 134$ & 0.38 \\
\hline End & $795 \pm 88$ & $860 \pm 124$ & \\
\hline \multicolumn{4}{|l|}{ Serum leptin, pg/mL } \\
\hline Baseline & $17,877 \pm 6153$ & $18,199 \pm 11,599$ & 0.42 \\
\hline End & $14,482 \pm 6184$ & $13,881 \pm 6825$ & \\
\hline \multicolumn{4}{|l|}{ Serum PAI-1, pg/mL * } \\
\hline Baseline & $4407 \pm 626$ & $3834 \pm 616$ & 0.02 \\
\hline End & $3329 \pm 1019$ & $3992 \pm 619$ & \\
\hline \multicolumn{4}{|l|}{ Serum resistin, $\mathrm{pg} / \mathrm{mL}$} \\
\hline Baseline & $8742 \pm 2705$ & $9321 \pm 1845$ & 0.37 \\
\hline End & $8280 \pm 2295$ & $7160 \pm 1902$ & \\
\hline \multicolumn{4}{|l|}{ Serum visfatin, $\mathrm{pg} / \mathrm{mL}$} \\
\hline Baseline & $8862 \pm 4406$ & $8323 \pm 1056$ & 0.03 \\
\hline End & $3409 \pm 1002$ & $6591 \pm 5851$ & \\
\hline
\end{tabular}

We also examined adjusted correlations among selected biomarkers of maternal antioxidant and adipokine biomarkers using a pooled analysis of 34 participants who completed the trial (Table 3). We observed a significant inverse correlation of serum glutathione and antioxidant capacity with PAI- 1 at baseline ( $\mathrm{r}:-0.32$ and -0.28 , respectively) and end of study ( $\mathrm{r}:-0.30$ and -0.33 , respectively) timepoints in adjusted models. Another significant correlation was a positive association of maternal serum MDA with visfatin at both time points (baseline r: 0.38 and study end r: 0.35$)$ in adjusted analyses $(p<0.05)$. 
Table 3. Partial correlation coefficients among maternal serum antioxidant, lipid oxidation and adipokine biomarkers adjusted for maternal age, BMI, and prenatal vitamin use at baseline and end of study.

\begin{tabular}{|c|c|c|c|c|}
\hline Variable by Time & Leptin & PAI-1 & Resistin & Visfatin \\
\hline \multicolumn{5}{|l|}{ Glutathione } \\
\hline Baseline & 0.04 & -0.32 & 0.04 & 0.03 \\
\hline End & 0.05 & -0.30 & 0.03 & 0.02 \\
\hline \multicolumn{5}{|l|}{ Antioxidant capacity } \\
\hline Baseline & 0.05 & -0.28 & -0.02 & 0.03 \\
\hline End & 0.06 & -0.33 & -0.02 & 0.02 \\
\hline \multicolumn{5}{|l|}{ MDA } \\
\hline Baseline & 0.07 & 0.06 & 0.03 & 0.38 \\
\hline End & 0.05 & 0.05 & 0.02 & 0.35 \\
\hline
\end{tabular}

Finally, we examined differences in maternal dietary intakes of trace elements with key roles in cellular antioxidant activities. As presented in Table 4, maternal habitual dietary intake of selenium was significantly increased over time, while no differences were noted in dietary intakes of iron, copper, zinc, and manganese. We previously reported no differences in dietary intakes of antioxidant vitamins (C and $\mathrm{E}$ ), fruits and vegetables in the intervention and control groups throughout the study [4].

Table 4. Maternal dietary intakes of trace elements as antioxidants following dietary intervention vs. control for 18 gestation weeks.

\begin{tabular}{|c|c|c|c|}
\hline Variable by Time & Intervention ${ }^{1}$ & Control $^{2}$ & $\begin{array}{l}p \text {-Value } \\
\text { (Group) }\end{array}$ \\
\hline \multicolumn{4}{|l|}{ Dietary iron, $\mathrm{mg} / \mathrm{d}$} \\
\hline Baseline & $20 \pm 3$ & $19 \pm 5$ & 0.46 \\
\hline End & $21 \pm 3$ & $20 \pm 4$ & \\
\hline \multicolumn{4}{|l|}{ Dietary Copper, $\mathrm{mg} / \mathrm{d}$} \\
\hline Baseline & $1.2 \pm 0.6$ & $0.8 \pm 0.7$ & 0.29 \\
\hline End & $1.3 \pm 0.7$ & $1.1 \pm 0.9$ & \\
\hline \multicolumn{4}{|l|}{ Dietary zinc, $\mathrm{mg} / \mathrm{d}$} \\
\hline Baseline & $8 \pm 7$ & $9 \pm 7$ & 0.34 \\
\hline End & $11 \pm 5$ & $10 \pm 6$ & \\
\hline \multicolumn{4}{|c|}{ Dietary selenium, $\mu \mathrm{g} / \mathrm{d}$ * } \\
\hline Baseline & $131 \pm 61$ & $151 \pm 55$ & 0.33 \\
\hline End & $176 \pm 84$ & $138 \pm 68$ & \\
\hline \multicolumn{4}{|c|}{ Dietary manganese, $\mathrm{mg} / \mathrm{d}$} \\
\hline Baseline & $4.2 \pm 2.6$ & $3.8 \pm 2.7$ & 0.42 \\
\hline End & $5.3 \pm 3.7$ & $4.6 \pm 1.9$ & \\
\hline
\end{tabular}

\section{Discussion}

We observed significant changes in maternal serum antioxidant and adipokine biomarkers following an intervention of blueberries and soluble fiber when compared to standard prenatal care group for a period of 18 gestation weeks in women at high risk for developing metabolic complications. Among the antioxidant biomarkers measured, maternal serum levels of reduced glutathione and antioxidant capacity increased, while MDA, a biomarker of lipid peroxidation, decreased following the dietary intervention. Among the adipokine biomarkers, maternal serum PAI-1 as well as visfatin decreased at the end of the dietary 
intervention as compared to the control group. We also observed a significant inverse correlation of maternal glutathione and antioxidant capacity with PAI-1, and a positive correlation between MDA and visfatin in models adjusted for maternal covariates, such as age, BMI, and prenatal vitamin use. These findings demonstrate an association between dietary intervention with antioxidants rich berries as well as optimized weight gain and an improved oxidative stress environment. It suggests that the low cost, well tolerated intervention in our study can improve pregnancy outcomes.

Obesity itself has been associated with increased oxidative stress and reduced antioxidant status [34], and thus pregnancies affected by obesity are more vulnerable to oxidative stress than those with normal pre-gestational body weight [35]. This suggests that adequate antioxidant protection throughout pregnancies at risk for obesity-related metabolic complications can improve outcomes. Unfortunately, antioxidant vitamins, such as vitamins $C$ and E may not effectively ameliorate oxidative stress as evidenced by several clinical trials in which antioxidant vitamin supplementation showed no effects in reducing risks of hypertensive complications of pregnancy, such as PE in high-risk women [36-38]. Plant-based Mediterranean (Med) or the Dietary Approaches to Stop Hypertension (DASH) diets containing a combination of several dietary bioactive compounds have been shown to be effective in reducing metabolic complications during pregnancy, such as GDM and PE in some studies, although not in others [39-41]. These studies do not always report maternal antioxidant, and hormonal and adipokine biomarkers, which may be important in determining their role in these metabolic complications, and may help explain the different results. When antioxidant activity has been reported, diet has been demonstrated to be effective in improving the antioxidant status. In a study of a sample size comparable to ours, Asemi et al. reported increases in maternal plasma antioxidant capacity and glutathione following DASH diet intervention for four weeks in women with GDM [39]. In another feeding trial, soy protein consumption led to improved maternal antioxidant capacity and glutathione levels in women with GDM [42]. In a third study of women at risk for PE, garlic supplementation was also shown to increase maternal plasma glutathione levels vs. placebo treatment [43]. The clinical observation that polyphenolic flavonoids, such as those found in blueberries can increase cellular glutathione synthesis and increase antioxidant capacity are consistent with these findings [44,45]. While the antioxidant enzyme activities did not differ between groups, there is a possibility that by increasing glutathione as a cofactor for the GR and GPX enzyme functions [46], the blueberry intervention prevented changes in their activities at the end of the study.

Adipokines, such as leptin, resistin, and visfatin, have been shown to be involved in signaling pathways between adipose tissue and key organs that are affected by insulin action, such as the skeletal muscle, liver, and pancreas [47,48]. Circulating levels of PAI-1 have been associated with insulin resistance and vascular complications $[49,50]$. As a result, maternal circulating adipokines have been correlated with risks of GDM and preeclampsia in observational studies [14,15]. Paradoxically, dietary intervention studies in pregnant women report effects on GWG but not on these biomarkers that contribute to obesity-related pathologies in pregnancy. Our study thus addresses this gap, as we measured a defined panel of maternal biomarkers of adipokines, as well as hormones that control food intake and glucose metabolism. A whole grain-based dietary intervention was shown to decrease serum PAI-1 in non-pregnant adults over a four-week period [51]. In addition, selected trials also show decreases in PAI-1 following a low carbohydrate diet, whole grain wheat, and omega-3-fatty acid supplementation in adults with cardiometabolic risks [52-54]. These findings, together with ours, warrant larger trials to identify adipokines that can be modulated by dietary bioactive compounds in reducing risks of metabolic complications during pregnancy in women with obesity.

Since our dietary intervention involved a combination of blueberries and soluble fiber, identifying their individual effects cannot be done accurately. While most of the effects on antioxidant biomarkers can be attributed to the high antioxidant content in blueberries [24], a few studies have reported antioxidant and anti-inflammatory effects of different kinds 
of soluble fiber in animal models of diabetes [55,56], and improvement of hyperglycemia in adults with diabetes $[57,58]$. Keeping in view the lack of studies involving soluble fiber supplementation in pregnant women, our findings warrant further investigation in larger trials.

Although weak, we also observed a positive correlation between serum lipid peroxidation and visfatin at baseline and at the end of study in our pooled sample analysis. Our findings are supported by a few observations in which maternal circulating MDA were positively correlated with adipokines in GDM [59]. Of interest, maternal serum visfatin has been shown to regulate oxidative stress and has been identified as a novel biomarker in predicting metabolic complications in obesity during pregnancy [60,61]. In line with this observation, we also found protective associations of maternal glutathione and serum antioxidant capacity with PAI-1, which may indicate that endogenous antioxidants, and subsequently an antioxidant-rich diet that promotes healthy GWG can be protective against metabolic complications in pregnancy [62,63].

The limitations of our study include the following: a sample of high-risk pregnant women with obesity and family history and/or history of GDM as a result of which findings cannot be generalized to women with normal gestational weight gain and at low risk for complications. Intervention initiated at $<20$ weeks gestation and biomarkers were measured at only two time points, and this precludes examining effects over the course of gestation, such as at first, second and third trimesters of gestation. Finally, we did not examine effects on these biomarkers during the pre-gestational and postpartum phases which are critical for physiological comparisons and this must be addressed in future studies. On the other hand, our study has unique strengths as follows: We measured a comprehensive panel of biomarkers involving maternal serum antioxidant activity, oxidative stress, and adipokines before and after dietary intervention of blueberries and soluble fiber vs. control group that has not been reported in other studies. We also measured maternal intakes of dietary trace elements, such as selenium, which are relevant to antioxidant enzyme activities, and found no differences between groups. Thus, the effects on antioxidant biomarkers can be attributed to the daily dietary intervention of blueberries and soluble fiber for 18 gestation weeks.

\section{Conclusions}

A healthy diet comprised of dietary bioactive compounds can ameliorate obesityrelated pathologies by improving the oxidative stress and antioxidant environment seen during pregnancies in women with obesity. Our study actively identifies antioxidant and adipokine biomarkers that are responsive to blueberry and soluble fiber supplementation in pregnant women with obesity and at high risk for gestational diabetes. The increases in serum glutathione and antioxidant capacity, as well as decreases in lipid peroxidation, PAI-I and visfatin reflect improved oxidative stress, inflammation, and adiposity function in these women and are consistent with the findings of improved clinical outcomes we previously reported.

Author Contributions: Conceptualization: A.B., J.L.E., P.P. and J.M.A.; methodology: A.B., J.C., J.W.K. and A.M.S.; investigation: A.B., J.L.E., P.P. and J.M.A.; formal analysis: A.B., J.C. and J.M.A.; writing—original draft: A.B., J.C. and J.L.E.; writing—review and editing: A.B., J.L.E., J.W.K., A.M.S., P.P. and J.M.A. All authors have read and agreed to the published version of the manuscript.

Funding: This publication was made possible by a grant from the National Institute of General Medical Sciences (GM103440) from the National Institutes of Health. Funding was also provided by the SIHS Dean's Faculty Development Award to A.B. at UNLV. Support was also received from the NIGMS P20 COBRE Award (5P20GM109025) (J.W.K.).

Institutional Review Board Statement: The study was conducted in accordance with the guidelines of the Declaration of Helsinki and approved by the Ethics Committee of the University of Nevada at Las Vegas (IRB\#1155039). Clinicaltrials.gov identifier NCT03467503. 
Informed Consent Statement: Informed consent was obtained from all subjects enrolled in and who completed the study.

Data Availability Statement: All generated data in this study are included in the article.

Conflicts of Interest: The authors declare no conflict of interest.

\section{References}

1. Catalano, P.M.; McIntyre, H.D.; Cruickshank, J.K.; McCance, D.R.; Dyer, A.R.; Metzger, B.E.; Lowe, L.P.; Trimble, E.R.; Coustan, D.R.; Hadden, D.R.; et al. The hyperglycemia and adverse pregnancy outcome study: Associations of GDM and obesity with pregnancy outcomes. Diabetes Care 2012, 35, 780-786. [CrossRef]

2. Catalano, P.M.; Shankar, K. Obesity and pregnancy: Mechanisms of short term and long term adverse consequences for mother and child. BMJ 2017, 356, j1. [CrossRef] [PubMed]

3. Muktabhant, B.; Lawrie, T.A.; Lumbiganon, P.; Laopaiboon, M. Diet or exercise, or both, for preventing excessive weight gain in pregnancy. Cochrane Database Syst. Rev. 2015, 6, Cd007145. [CrossRef]

4. Basu, A.; Feng, D.; Planinic, P.; Ebersole, J.L.; Lyons, T.J.; Alexander, J.M. Dietary Blueberry and Soluble Fiber Supplementation Reduces Risk of Gestational Diabetes in Women with Obesity in a Randomized Controlled Trial. J. Nutr. 2021, 151, 1128-1138. [CrossRef]

5. Effect of diet and physical activity based interventions in pregnancy on gestational weight gain and pregnancy outcomes: Meta-analysis of individual participant data from randomised trials. BMJ 2017, 358, j3119. [CrossRef]

6. Agarwal, A.; Gupta, S.; Sharma, R.K. Role of oxidative stress in female reproduction. Reprod. Biol. Endocrinol. RBE 2005, 3, 28. [CrossRef]

7. Burton, G.J.; Jauniaux, E. Oxidative stress. Best Pract. Res. Clin. Obstet. Gynaecol. 2011, 25, 287-299. [CrossRef] [PubMed]

8. Chiarello, D.I.; Abad, C.; Rojas, D.; Toledo, F.; Vázquez, C.M.; Mate, A.; Sobrevia, L.; Marín, R. Oxidative stress: Normal pregnancy versus preeclampsia. Biochim. Biophys. Acta Mol. Basis Dis. 2020, 1866, 165354. [CrossRef] [PubMed]

9. Parast, V.M.; Paknahad, Z. Antioxidant Status and Risk of Gestational Diabetes Mellitus: A Case-Control Study. Clin. Nutr. Res. 2017, 6, 81-88. [CrossRef] [PubMed]

10. Askari, G.; Iraj, B.; Salehi-Abargouei, A.; Fallah, A.A.; Jafari, T. The association between serum selenium and gestational diabetes mellitus: A systematic review and meta-analysis. J. Trace Elem. Med. Biol. Organ Soc. Miner. Trace Elem. (GMS) 2015, $29,195-201$. [CrossRef] [PubMed]

11. Sen, S.; Iyer, C.; Meydani, S.N. Obesity during pregnancy alters maternal oxidant balance and micronutrient status. J. Perinatol. 2014, 34, 105-111. [CrossRef]

12. Ballesteros-Guzmán, A.K.; Carrasco-Legleu, C.E.; Levario-Carrillo, M.; Chávez-Corral, D.V.; Sánchez-Ramírez, B.; MariñelarenaCarrillo, E.O.; Guerrero-Salgado, F.; Reza-López, S.A. Prepregnancy Obesity, Maternal Dietary Intake, and Oxidative Stress Biomarkers in the Fetomaternal Unit. BioMed Res. Int. 2019, 2019, 5070453. [CrossRef]

13. Bao, W.; Baecker, A.; Song, Y.; Kiely, M.; Liu, S.; Zhang, C. Adipokine levels during the first or early second trimester of pregnancy and subsequent risk of gestational diabetes mellitus: A systematic review. Metab. Clin. Exp. 2015, 64, 756-764. [CrossRef]

14. Reith, A.; Booth, N.A.; Moore, N.R.; Cruickshank, D.J.; Bennett, B. Plasminogen activator inhibitors (PAI-1 and PAI-2) in normal pregnancies, pre-eclampsia and hydatidiform mole. Br. J. Obstet. Gynaecol. 1993, 100, 370-374. [CrossRef] [PubMed]

15. Noureldeen, A.F.; Qusti, S.Y.; Al-Seeni, M.N.; Bagais, M.H. Maternal leptin, adiponectin, resistin, visfatin and tumor necrosis factor-alpha in normal and gestational diabetes. Indian J. Clin. Biochem. IJCB 2014, 29, 462-470. [CrossRef] [PubMed]

16. Basu, A.; Morris, S.; Nguyen, A.; Betts, N.M.; Fu, D.; Lyons, T.J. Effects of Dietary Strawberry Supplementation on Antioxidant Biomarkers in Obese Adults with Above Optimal Serum Lipids. J. Nutr. Metab. 2016, 2016, 3910630. [CrossRef] [PubMed]

17. Basu, A.; Izuora, K.; Betts, N.M.; Kinney, J.W.; Salazar, A.M.; Ebersole, J.L.; Scofield, R.H. Dietary Strawberries Improve Cardiometabolic Risks in Adults with Obesity and Elevated Serum LDL Cholesterol in a Randomized Controlled Crossover Trial. Nutrients 2021, 13, 1421. [CrossRef] [PubMed]

18. Basu, A.; Betts, N.M.; Mulugeta, A.; Tong, C.; Newman, E.; Lyons, T.J. Green tea supplementation increases glutathione and plasma antioxidant capacity in adults with the metabolic syndrome. Nutr. Res. 2013, 33, 180-187. [CrossRef]

19. Panahi, Y.; Hosseini, M.S.; Khalili, N.; Naimi, E.; Majeed, M.; Sahebkar, A. Antioxidant and anti-inflammatory effects of curcuminoid-piperine combination in subjects with metabolic syndrome: A randomized controlled trial and an updated metaanalysis. Clin. Nutr. 2015, 34, 1101-1108. [CrossRef]

20. Hoseini, A.; Namazi, G.; Farrokhian, A.; Reiner, Ž.; Aghadavod, E.; Bahmani, F.; Asemi, Z. The effects of resveratrol on metabolic status in patients with type 2 diabetes mellitus and coronary heart disease. Food Funct. 2019, 10, 6042-6051. [CrossRef]

21. Wedick, N.M.; Pan, A.; Cassidy, A.; Rimm, E.B.; Sampson, L.; Rosner, B.; Willett, W.; Hu, F.B.; Sun, Q.; van Dam, R.M. Dietary flavonoid intakes and risk of type 2 diabetes in US men and women. Am. J. Clin. Nutr. 2012, 95, 925-933. [CrossRef]

22. Cassidy, A.; O’Reilly, E.J.; Kay, C.; Sampson, L.; Franz, M.; Forman, J.P.; Curhan, G.; Rimm, E.B. Habitual intake of flavonoid subclasses and incident hypertension in adults. Am. J. Clin. Nutr. 2011, 93, 338-347. [CrossRef] [PubMed]

23. Calvano, A.; Izuora, K.; Oh, E.C.; Ebersole, J.L.; Lyons, T.J.; Basu, A. Dietary berries, insulin resistance and type 2 diabetes: An overview of human feeding trials. Food Funct. 2019, 10, 6227-6243. [CrossRef] [PubMed] 
24. Basu, A.; Du, M.; Leyva, M.J.; Sanchez, K.; Betts, N.M.; Wu, M.; Aston, C.E.; Lyons, T.J. Blueberries decrease cardiovascular risk factors in obese men and women with metabolic syndrome. J. Nutr. 2010, 140, 1582-1587. [CrossRef] [PubMed]

25. Basu, A.; Betts, N.M.; Nguyen, A.; Newman, E.D.; Fu, D.; Lyons, T.J. Freeze-dried strawberries lower serum cholesterol and lipid peroxidation in adults with abdominal adiposity and elevated serum lipids. J. Nutr. 2014, 144, 830-837. [CrossRef]

26. Basu, A.; Betts, N.M.; Ortiz, J.; Simmons, B.; Wu, M.; Lyons, T.J. Low-energy cranberry juice decreases lipid oxidation and increases plasma antioxidant capacity in women with metabolic syndrome. Nutr. Res. 2011, 31, 190-196. [CrossRef]

27. Jovanovski, E.; Khayyat, R.; Zurbau, A.; Komishon, A.; Mazhar, N.; Sievenpiper, J.L.; Blanco Mejia, S.; Ho, H.V.T.; Li, D.; Jenkins, A.L.; et al. Should Viscous Fiber Supplements Be Considered in Diabetes Control? Results from a Systematic Review and Meta-analysis of Randomized Controlled Trials. Diabetes Care 2019, 42, 755-766. [CrossRef]

28. Zhang, C.; Liu, S.; Solomon, C.G.; Hu, F.B. Dietary fiber intake, dietary glycemic load, and the risk for gestational diabetes mellitus. Diabetes Care 2006, 29, 2223-2230. [CrossRef]

29. Zhang, X.; Gong, Y.; Della Corte, K.; Yu, D.; Xue, H.; Shan, S.; Tian, G.; Liang, Y.; Zhang, J.; He, F.; et al. Relevance of dietary glycemic index, glycemic load and fiber intake before and during pregnancy for the risk of gestational diabetes mellitus and maternal glucose homeostasis. Clin. Nutr. 2021, 40, 2791-2799. [CrossRef]

30. Anderson, J.W.; Baird, P.; Davis, R.H., Jr.; Ferreri, S.; Knudtson, M.; Koraym, A.; Waters, V.; Williams, C.L. Health benefits of dietary fiber. Nutr. Rev. 2009, 67, 188-205. [CrossRef]

31. Beutler, E.; Duron, O.; Kelly, B.M. Improved method for the determination of blood glutathione. J. Lab. Clin. Med. 1963, 61, 882-888. [PubMed]

32. Miller, N.J.; Rice-Evans, C.; Davies, M.J.; Gopinathan, V.; Milner, A. A novel method for measuring antioxidant capacity and its application to monitoring the antioxidant status in premature neonates. Clin. Sci. 1993, 84, 407-412. [CrossRef] [PubMed]

33. Jain, S.K.; McVie, R.; Duett, J.; Herbst, J.J. Erythrocyte membrane lipid peroxidation and glycosylated hemoglobin in diabetes. Diabetes 1989, 38, 1539-1543. [CrossRef]

34. Lechuga-Sancho, A.M.; Gallego-Andujar, D.; Ruiz-Ocaña, P.; Visiedo, F.M.; Saez-Benito, A.; Schwarz, M.; Segundo, C.; Mateos, R.M. Obesity induced alterations in redox homeostasis and oxidative stress are present from an early age. PLoS ONE 2018, 13, e0191547. [CrossRef] [PubMed]

35. Malti, N.; Merzouk, H.; Merzouk, S.A.; Loukidi, B.; Karaouzene, N.; Malti, A.; Narce, M. Oxidative stress and maternal obesity: Feto-placental unit interaction. Placenta 2014, 35, 411-416. [CrossRef]

36. McCance, D.R.; Holmes, V.A.; Maresh, M.J.; Patterson, C.C.; Walker, J.D.; Pearson, D.W.; Young, I.S. Vitamins C and E for prevention of pre-eclampsia in women with type 1 diabetes (DAPIT): A randomised placebo-controlled trial. Lancet 2010, 376, 259-266. [CrossRef]

37. Kalpdev, A.; Saha, S.C.; Dhawan, V. Vitamin C and E supplementation does not reduce the risk of superimposed PE in pregnancy. Hypertens. Pregnancy 2011, 30, 447-456. [CrossRef]

38. Poston, L.; Briley, A.L.; Seed, P.T.; Kelly, F.J.; Shennan, A.H. Vitamin C and vitamin E in pregnant women at risk for pre-eclampsia (VIP trial): Randomised placebo-controlled trial. Lancet 2006, 367, 1145-1154. [CrossRef]

39. Asemi, Z.; Samimi, M.; Tabassi, Z.; Sabihi, S.S.; Esmaillzadeh, A. A randomized controlled clinical trial investigating the effect of DASH diet on insulin resistance, inflammation, and oxidative stress in gestational diabetes. Nutrition 2013, 29, 619-624. [CrossRef]

40. Cao, Y.; Liu, Y.; Zhao, X.; Duan, D.; Dou, W.; Fu, W.; Chen, H.; Bo, Y.; Qiu, Y.; Chen, G.; et al. Adherence to a Dietary Approaches to Stop Hypertension (DASH)-style Diet in Relation to Preeclampsia: A Case-Control Study. Sci. Rep. 2020, 10, 9078. [CrossRef]

41. Ha, V.; Bonner, A.J.; Jadoo, J.K.; Beyene, J.; Anand, S.S.; de Souza, R.J. The effects of various diets on glycemic outcomes during pregnancy: A systematic review and network meta-analysis. PLoS ONE 2017, 12, e0182095. [CrossRef] [PubMed]

42. Jamilian, M.; Asemi, Z. The Effect of Soy Intake on Metabolic Profiles of Women With Gestational Diabetes Mellitus. J. Clin. Endocrinol. Metab. 2015, 100, 4654-4661. [CrossRef] [PubMed]

43. Aalami-Harandi, R.; Karamali, M.; Asemi, Z. The favorable effects of garlic intake on metabolic profiles, hs-CRP, biomarkers of oxidative stress and pregnancy outcomes in pregnant women at risk for pre-eclampsia: Randomized, double-blind, placebocontrolled trial. J. Matern. Fetal Neonatal Med. 2015, 28, 2020-2027. [CrossRef]

44. Moskaug, J.O.; Carlsen, H.; Myhrstad, M.C.; Blomhoff, R. Polyphenols and glutathione synthesis regulation. Am. J. Clin. Nutr. 2005, 81, 277S-283S. [CrossRef] [PubMed]

45. Myhrstad, M.C.; Carlsen, H.; Nordström, O.; Blomhoff, R.; Moskaug, J. Flavonoids increase the intracellular glutathione level by transactivation of the gamma-glutamylcysteine synthetase catalytical subunit promoter. Free Radic. Biol. Med. 2002, 32, 386-393. [CrossRef]

46. Lu, J.; Holmgren, A. The thioredoxin antioxidant system. Free Radic. Biol. Med. 2014, 66, 75-87. [CrossRef]

47. Zavalza-Gómez, A.B.; Anaya-Prado, R.; Rincón-Sánchez, A.R.; Mora-Martínez, J.M. Adipokines and insulin resistance during pregnancy. Diabetes Res. Clin. Pract. 2008, 80, 8-15. [CrossRef]

48. Kumari, B.; Yadav, U.C.S. Adipokine Visfatin's Role in Pathogenesis of Diabesity and Related Metabolic Derangements. Curr. Mol. Med. 2018, 18, 116-125. [CrossRef]

49. Supriya, R.; Tam, B.T.; Yu, A.P.; Lee, P.H.; Lai, C.W.; Cheng, K.K.; Yau, S.Y.; Chan, L.W.; Yung, B.Y.; Sheridan, S.; et al. Adipokines demonstrate the interacting influence of central obesity with other cardiometabolic risk factors of metabolic syndrome in Hong Kong Chinese adults. PLOS ONE 2018, 13, e0201585. [CrossRef] 
50. Alessi, M.C.; Juhan-Vague, I. PAI-1 and the metabolic syndrome: Links, causes, and consequences. Arterioscler. Thromb. Vasc. Biol. 2006, 26, 2200-2207. [CrossRef] [PubMed]

51. Kim, Y.; Keogh, J.B.; Clifton, P.M. Effects of Two Different Dietary Patterns on Inflammatory Markers, Advanced Glycation End Products and Lipids in Subjects without Type 2 Diabetes: A Randomised Crossover Study. Nutrients 2017, 9, 336. [CrossRef]

52. Forsythe, C.E.; Phinney, S.D.; Fernandez, M.L.; Quann, E.E.; Wood, R.J.; Bibus, D.M.; Kraemer, W.J.; Feinman, R.D.; Volek, J.S. Comparison of low fat and low carbohydrate diets on circulating fatty acid composition and markers of inflammation. Lipids 2008, 43, 65-77. [CrossRef] [PubMed]

53. Mehta, J.; Lawson, D.; Saldeen, T.J. Reduction in plasminogen activator inhibitor-1 (PAI-1) with omega-3 polyunsaturated fatty acid (PUFA) intake. Am. Heart J. 1988, 116, 1201-1206. [CrossRef]

54. Vitaglione, P.; Mennella, I.; Ferracane, R.; Rivellese, A.A.; Giacco, R.; Ercolini, D.; Gibbons, S.M.; La Storia, A.; Gilbert, J.A.; Jonnalagadda, S.; et al. Whole-grain wheat consumption reduces inflammation in a randomized controlled trial on overweight and obese subjects with unhealthy dietary and lifestyle behaviors: Role of polyphenols bound to cereal dietary fiber. Am. J. Clin. Nutr. 2015, 101, 251-261. [CrossRef] [PubMed]

55. Zhao, Y.; Jayachandran, M.; Xu, B. In vivo antioxidant and anti-inflammatory effects of soluble dietary fiber Konjac glucomannan in type-2 diabetic rats. Int. J. Biol. Macromol. 2020, 159, 1186-1196. [CrossRef]

56. Jayachandran, M.; Chen, J.; Chung, S.S.M.; Xu, B. A critical review on the impacts of $\beta$-glucans on gut microbiota and human health. J. Nutr. Biochem. 2018, 61, 101-110. [CrossRef]

57. De Carvalho, C.M.; de Paula, T.P.; Viana, L.V.; Machado, V.M.; de Almeida, J.C.; Azevedo, M.J. Plasma glucose and insulin responses after consumption of breakfasts with different sources of soluble fiber in type 2 diabetes patients: A randomized crossover clinical trial. Am. J. Clin. Nutr. 2017, 106, 1238-1245. [CrossRef]

58. Würsch, P.; Pi-Sunyer, F.X. The role of viscous soluble fiber in the metabolic control of diabetes. A review with special emphasis on cereals rich in beta-glucan. Diabetes Care 1997, 20, 1774-1780. [CrossRef]

59. Shang, M.; Dong, X.; Hou, L. Correlation of adipokines and markers of oxidative stress in women with gestational diabetes mellitus and their newborns. J. Obstet. Gynaecol. Res. 2018, 44, 637-646. [CrossRef]

60. Wnuk, A.; Stangret, A.; Watroba, M.; Płatek, A.E.; Skoda, M.; Cendrowski, K.; Sawicki, W.; Szukiewicz, D. Can adipokine visfatin be a novel marker of pregnancy-related disorders in women with obesity? Obes. Rev. 2020, 21, e13022. [CrossRef]

61. Mazaki-Tovi, S.; Romero, R.; Kusanovic, J.P.; Vaisbuch, E.; Erez, O.; Than, N.G.; Chaiworapongsa, T.; Nhan-Chang, C.L.; Pacora, P.; Gotsch, F.; et al. Maternal visfatin concentration in normal pregnancy. J. Perinat. Med. 2009, 37, 206-217. [CrossRef] [PubMed]

62. Stringa, N.; Brahimaj, A.; Zaciragic, A.; Dehghan, A.; Ikram, M.A.; Hofman, A.; Muka, T.; Kiefte-de Jong, J.C.; Franco, O.H. Relation of antioxidant capacity of diet and markers of oxidative status with C-reactive protein and adipocytokines: A prospective study. Metab. Clin. Exp. 2017, 71, 171-181. [CrossRef] [PubMed]

63. Lubrano, C.; Valacchi, G.; Specchia, P.; Gnessi, L.; Rubanenko, E.P.; Shuginina, E.A.; Trukhanov, A.I.; Korkina, L.G.; De Luca, C. Integrated Haematological Profiles of Redox Status, Lipid, and Inflammatory Protein Biomarkers in Benign Obesity and Unhealthy Obesity with Metabolic Syndrome. Oxidative Med. Cell. Longev. 2015, 2015, 490613. [CrossRef] [PubMed] 